\title{
Service learning with First Peoples: A framework to support respectful and reciprocal learning
}

\section{Brydie-Leigh Bartleet ${ }^{1}$, Dawn Bennett ${ }^{2}$, Anne Power ${ }^{3}$, Naomi Sunderland ${ }^{4}$}

${ }^{1}$ Queensland Conservatorium Griffith University, Brisbane, Australia

${ }^{2}$ Curtin University, Perth, Australia

${ }^{3}$ Western Sydney University, Sydney, Australia

${ }^{4}$ Griffith University, Brisbane, Australia

Corresponding author: Brydie-Leigh Bartleet, + 6173735 6249, b.bartleet@griffith.edu.au

This article outlines a framework for working with First Peoples in an arts-based service learning context. The framework is designed to support respectful and mutually beneficial learning partnerships through three, interconnected Ways of Knowing, Ways of Being, and Ways of Doing. To set the context for this framework, the article first offers insights from the literature on global service learning and service learning with First Peoples, and next describes the research context that led to this framework. It then outlines the article's framework, by drawing on examples from three arts-based service learning programmes with Aboriginal communities over eight years.

\section{Keywords}

First Peoples 
Arts-based service learning

Intercultural learning

Framework for practice and evaluation

Higher education

\section{Introduction}

Universities worldwide are acknowledging the role of international study experiences in developing graduates with the intercultural competencies and proficiencies needed to function as global citizens. Global service learning (GSL) has played a significant role, providing students with opportunities to develop strong working relationships with international partners across a range of cultural contexts on projects of community significance (McMillan \& Stanton, 2014; see also Green, 2009; Lewin, 2010).

Many GSL programmes involve culturally immersive experiences that develop students' intercultural competencies and prompt critical reflections on their cultural subjectivities, power, privilege, and hegemonic assumptions (Hartman \& Kiely, 2014). These developments resonate with parallel work in service learning with First Peoples. Both approaches share a focus on rich and multi-layered learning processes and outcomes that can occur at the interface of cultures (see Nakata, 2002), whether at home or abroad (Longo \& Saltmarsh, 2011). The approaches also share similar tensions, and indeed possibilities, when working across cultures in ways that embrace First Peoples' worldviews and embody anti-colonial practices (see Dei \& Kempf, 2006; Hart, 2010).

\section{First Peoples and Service Learning}


Broader discussions of service learning for social justice and change (see Mitchell \& Humphries, 2007), multicultural service learning (see Boyle-Baise et al., 2006) and "interracial” service learning (see Murphy \& Rasch, 2008) offer important insights on the socio-political and intercultural dimensions of service learning with First Peoples. Until recently, however, little literature has focused on service learning with First Peoples, and even less has conceptualised service learning from First Peoples' perspectives. Guffey (2008) asserts the need for strong links between service learning and First Peoples' worldviews including spiritual connections with the earth and the significance of storytelling. Molnar (2010, p. 11) adds the need to position community members as capable agents and reciprocal learning partners (Porter \& Monard, 2001) rather than 'people in need of being saved'.

In his service learning work with American Indian tribal nations, Steinman (2011) explains that personal interactions and 'witnessing' can transform learner and the relationships between partners. Steinman contributes to the theorisation of service and the value of 'making space' for the integration of Indigenous worldviews in service-learning courses. Crucially, making space includes hearing First Peoples and engaging in intercultural dialogue on their terms: 'closing the relational gap' rather than 'spectating ... a privilege where the self is distanced and separated' (Steinman, 2011, p. 12).

Making space also emerges as a vehicle for de-centring the perspectives of dominant social groups, creating deeper and more communityoriented relationships, and heightening participants' personal awareness of their location within, and participation in, social inequalities. This 
way of relating to one another unfolds dynamically in social spaces and is deeply informed by First Peoples' perspectives. Making space can promote what McMillan and Stanton (2014) call learning service (see also Boyle-Baise et al., 2006) to promote deep critical reflection and change.

\section{Our arts-based service learning programmes}

This article shares findings from one of the first in-depth studies to look into service learning programmes with First Peoples of Australia. It draws together eight years of practice and research in service learning with Aboriginal communities (2009-2017) and a three-year nationally funded project (2011-2014) that entailed collaborative research across arts-based service learning (ABSL) programmes at three Australian universities, including Queensland Conservatorium Griffith University (Brisbane), Western Sydney University (Sydney) and Curtin University (Perth) in partnership with Aboriginal communities in metropolitan Perth and remote Tennant Creek (Northern Territory). Students worked alongside Aboriginal artists and Elders on community-led projects such as song writing and recording, arts festival production, school-based educational programmes, and film and journalism initiatives. (We have documented these programmes in detail elsewhere: see for example Bartleet, et. al., 2014b; Bartleet, et. al., 2016; Power \& Bennett, 2015.)

Students in each institution were invited to submit an Expression of Interest. Selection was based on students' skills sets and their alignment with the needs of the community projects involved in each programme. The selected students were then invited to enrol in an ABSL programme for credit at their respective institutions. 


\section{Methods, ethics and analysis}

This article draws on the collaborative research undertaken across the three universities, and seeks to answer one of the broader project's core question: How can arts-based service-learning programmes with First Peoples be designed to engender strong relationships between culture bearers and students, and support respectful and reciprocal ways of learning?

Participating students $(N=124)$ came from music, film and television, pre-service teachers with a major in the arts, and journalism. Following Swords and Kiely's (2010) suggestion that the most powerful transformative learning experiences occur in service learning through critical reflection before, during, and after the programme, we collected reflective data through semi-structured interviews (with community members, faculty and students), student assessment and reflection tasks (in the form of digital stories and reflective journals), and researcher reflective diaries and observations. We also used unstructured diary writing and video and photo observation techniques to document the contexts within which the programmes occurred.

Ethical clearance was obtained from each institution's ethics review committee in order to collect this reflective data. The study used standard informed consent mechanisms, with information sheets in plain English. We remain in contact with the communities to ensure that appropriate cultural protocols continue to be observed: for example, removing public images and music featuring deceased participants. ${ }^{\mathrm{i}}$ 
Analysis began with a preliminary thematic coding schema developed through our previous work (Bartleet, et. al., 2014a). Once the data were cleaned, team members coded selections of the new data and provided input and feedback on the schema. Inter-rater reliability using the revised schema met a cut-off point of $80 \%$ (Miles \& Huberman, 1994). The next wave of analysis involved a series of face-to-face meetings to develop meta-ethnographic interpretations of the experiences and outcomes reported in participants' accounts. Once completed, the draft analysis was presented to an external evaluator and a national Advisory Group of leading Aboriginal colleagues, stakeholders, and experts. This led to a distillation of key findings into a Framework for practice.

\section{A Framework to support respectful and reciprocal learning}

Across the ABSL programmes, data revealed three interconnected elements of learning broadly understood as ways of knowing, being, and doing. Seeking to conceptualise these, we found inspiration and insights in the work of Aboriginal scholar Karen Booran Mirraboopa Martin (2003), whose Quandamooka worldview encapsulates all three elements. By re-organising the data according to a Quandamooka worldview, we identified nine enablers of intercultural engagement in service learning, which are shown in the following Framework (Table 1, see also Bartleet, et. al., 2014b). In the following sections, we draw on participant insights and the service learning literature to illustrate how the Quandamooka worldview can occur in practice.

Table 1. Conceptual Framework with suggestions for practice 


\begin{tabular}{|c|c|c|c|}
\hline $\begin{array}{ll}\text { Ways } & \text { of } \\
\text { learning }\end{array}$ & Ways of engaging & Key insights derived from the project & Suggestions for practice \\
\hline \multirow[t]{3}{*}{ Knowing } & $\begin{array}{l}\text { Sitting down on } \\
\text { country }\end{array}$ & $\begin{array}{l}\text { Whether the ABSL program involves } \\
\text { travelling to a remote, far away country or } \\
\text { rediscovering the country that one regularly } \\
\text { lives on, a very necessary step is to slow } \\
\text { down, observe and connect with the country } \\
\text { and its people. This will most likely ensure a } \\
\text { much deeper engagement for all concerned. }\end{array}$ & $\begin{array}{l}\text { - Follow cultural protocols and sit down with Elders } \\
\text { before commencing an ABSL program. This is an } \\
\text { appropriate way to connect with country and people. } \\
\text { - Ask an Elder whether they would be prepared to take } \\
\text { the students on a site visit, to learn about places of } \\
\text { significance and busk tucker, for example. } \\
\text { - Take students on a sensory walk at the beginning of the } \\
\text { ABSL. }\end{array}$ \\
\hline & $\begin{array}{l}\text { Respecting culture \& } \\
\text { First Peoples' } \\
\text { worldviews }\end{array}$ & $\begin{array}{l}\text { When value is placed on respecting and } \\
\text { learning about Aboriginal culture and } \\
\text { worldviews from Elders and the artists } \\
\text { themselves, we begin to take a vital step } \\
\text { towards embedding Aboriginal and Torres } \\
\text { Strait Islander curriculum content in a way } \\
\text { that privileges the holders of that content. }\end{array}$ & $\begin{array}{l}\text { - Organise cultural awareness classes as part of your } \\
\text { ABSL orientation project to prioritise the learning of } \\
\text { First Peoples' culture and worldviews. } \\
\text { - Arrange for culture and language lessons during the } \\
\text { ABSL project so that students can seek advice about } \\
\text { cultural protocols from Elders as they come to hand. } \\
\text { - Provide students with readings about Aboriginal } \\
\text { culture and following cultural protocols ahead of the } \\
\text { ABSL project }\end{array}$ \\
\hline & $\begin{array}{l}\text { Transforming } \\
\text { understandings \& } \\
\text { worldviews through } \\
\text { critical reflection }\end{array}$ & $\begin{array}{l}\text { When critical reflection accompanies the } \\
\text { embodied and emplaced learning experiences } \\
\text { in ABSL programs, participants have the } \\
\text { potential to experience deep and long-lasting } \\
\text { lessons that radically transform their } \\
\text { understandings of themselves, their arts- } \\
\text { practice, and the world around them. }\end{array}$ & $\begin{array}{l}\text { - Use guided reflection tools such as reflective diaries } \\
\text { with prompts \& questions about the experience. } \\
\text { - Incorporate regular informal de-briefs for the group to } \\
\text { off-load and speak frankly about their thoughts and } \\
\text { experiences. } \\
\text { - Undertake semi-structured interviews with students } \\
\text { to prompt reflection and discussion on a one-to-one } \\
\text { basis. }\end{array}$ \\
\hline
\end{tabular}




\begin{tabular}{|c|c|c|c|}
\hline $\begin{array}{ll}\text { Ways } & \text { of } \\
\text { learning } & \\
\end{array}$ & Ways of engaging & Key insights derived from the project & Suggestions for practice \\
\hline \multirow[t]{3}{*}{ Being } & $\begin{array}{l}\text { Building and } \\
\text { deepening } \\
\text { relationships }\end{array}$ & $\begin{array}{l}\text { Taking the time to develop trusting } \\
\text { relationships with people and partners is the } \\
\text { most fundamentally important part of this } \\
\text { work. These relationships underpin } \\
\text { everything that is learned and experienced on } \\
\text { these ABSL programs, and without them any } \\
\text { kind of meaningful engagement is not } \\
\text { possible. }\end{array}$ & $\begin{array}{l}\text { - Prioritise building trusting relationships with } \\
\text { participants instead of focusing on your own agenda } \\
\text { and the tasks at hand. } \\
\text { - Arrange for community consultations to occur, where } \\
\text { you discuss process, aims, and ways of working, long } \\
\text { before a student group is introduced to the community. } \\
\text { - Realise that relationships take time to build, and this } \\
\text { may take a number of years. Be patient! }\end{array}$ \\
\hline & $\begin{array}{l}\text { Learning \& sharing in } \\
\text { reciprocal ways }\end{array}$ & $\begin{array}{l}\text { Embracing an asset-based approach to ABSL } \\
\text { programs allows us to become attuned to the } \\
\text { reciprocal and mutually beneficial ways in } \\
\text { which participants learn from one another in } \\
\text { these contexts. When viewed this way all } \\
\text { participants are active learners with } \\
\text { something valuable to share. }\end{array}$ & $\begin{array}{l}\text { - Give participants time to jam and collaborate with } \\
\text { one another. This quite often will organically lead to } \\
\text { sharing, reciprocity and mutual leaning. } \\
\text { - Reflect on the ABSL project using an asset-based } \\
\text { approach, where you view all participants as active } \\
\text { learners with something to contribute. }\end{array}$ \\
\hline & $\begin{array}{l}\text { Responding to } \\
\text { contextual politics \& } \\
\text { dynamics with } \\
\text { sensitivity }\end{array}$ & $\begin{array}{l}\text { These ABSL programs are often set amidst } \\
\text { deeply complex contexts with politics and } \\
\text { dynamics that are difficult to grapple with, to } \\
\text { say the least. While this might result in a } \\
\text { degree of apprehension from all participants, } \\
\text { this can be mitigated to a degree with } \\
\text { sensitivity, humanity and a good dose of } \\
\text { humour. }\end{array}$ & $\begin{array}{l}\text { - Have regular de-briefs with program teams, or } \\
\text { Advisory Groups, to discuss appropriate and sensitive } \\
\text { responses to topics as they come to hand. }\end{array}$ \\
\hline
\end{tabular}




\begin{tabular}{|c|c|c|c|}
\hline $\begin{array}{ll}\text { Ways } & \text { of } \\
\text { learning }\end{array}$ & Ways of engaging & Key insights derived from the project & Suggestions for practice \\
\hline \multirow[t]{3}{*}{ Doing } & $\begin{array}{l}\text { Using the arts as a } \\
\text { medium for } \\
\text { connection \& } \\
\text { collaboration }\end{array}$ & $\begin{array}{l}\text { In service learning with First Peoples, arts- } \\
\text { based processes commonly provide } \\
\text { culturally appropriate ways of expression, } \\
\text { communication and connection with one } \\
\text { another, and provide an opportunity to } \\
\text { creatively share life experiences and } \\
\text { appreciate one another's strengths. }\end{array}$ & $\begin{array}{l}\text { - Look out for ways to respond to community needs } \\
\text { with a creative solution that everyone can work on } \\
\text { collaboratively. } \\
\text { - Draw on local musicians and artists (they will always } \\
\text { be there, seek them out) to be part of your work, so that } \\
\text { the ABSL project becomes part of the community and } \\
\text { continues even if you are not there. }\end{array}$ \\
\hline & $\begin{array}{l}\text { Designing \& } \\
\text { implementing ABSL } \\
\text { projects to meet both } \\
\text { community \& } \\
\text { institutional needs }\end{array}$ & $\begin{array}{l}\text { When designing ABSL programs with First } \\
\text { Peoples, a delicate balance needs to be } \\
\text { achieved between meeting the community } \\
\text { needs and meeting the institution's } \\
\text { requirements in terms of resourcing, } \\
\text { recruitment, assessment, curriculum design, } \\
\text { and policy compliance. A sense of shared } \\
\text { ownership is vital for ongoing, mutual } \\
\text { engagement. }\end{array}$ & $\begin{array}{l}\text { - Keep the channels of communication open with } \\
\text { community leaders to ensure that community } \\
\text { ownership of the project occurs, and the community } \\
\text { guide the processes you're following. } \\
\text { - Report up to institutional management to ensure that } \\
\text { the project meets the requirements of the university, but } \\
\text { also shares its innovative approaches to learning and } \\
\text { teaching with others. } \\
\text { - Build in peer support for facilitators and participants } \\
\text { of these projects to ensure necessary support is given. }\end{array}$ \\
\hline & $\begin{array}{l}\text { Building sustainability } \\
\text { into ABSL projects }\end{array}$ & $\begin{array}{l}\text { Building sustainability into ABSL programs } \\
\text { with First Peoples involves making a } \\
\text { commitment to developing ongoing } \\
\text { relationships, developing community assets } \\
\text { and strengths, and supporting participant } \\
\text { morale amid frequently challenging } \\
\text { circumstances. }\end{array}$ & $\begin{array}{l}\text { - When designing these projects, factor in the significant } \\
\text { hard and soft infrastructure that is needed, and realise } \\
\text { that starting small is often a wise move. } \\
\text { - Be in it for the long haul and be prepared to put in a } \\
\text { significant investment of time and energy. Be prepared } \\
\text { to have your life and worldview changed, possibly for } \\
\text { the better. }\end{array}$ \\
\hline
\end{tabular}




\section{Ways of Knowing}

In our ABSL programmes, Ways of Knowing were learned and reproduced through sitting, watching, waiting, listening and much else. The Ways of Knowing responded to contextual factors such as Sorry Business ${ }^{\mathrm{ii}}$ or the negotiation of gender-related dynamics or particular kinship relationships such as Avoidance ${ }^{\mathrm{iii}}$. As such, our ABSL programmes needed to incorporate sensitivity toward both contexts and processes. Rather than arrive with preconceived agendas, students and faculty members needed to first sit down and talk with collaborators, to share control, to be sensitive to things that were going on in the community, and to respect this relational way of working. To unpack this further, in the following section we draw from the data to illustrate how these Ways of Knowing can encompass different ways of engaging with people, culture and communities: (a) sitting down on country; (b) respecting culture and First Peoples' worldviews; and (c) transforming understandings and worldviews through critical reflection.

\section{Sitting down on country}

A recurring theme was the importance of literally sitting down on country ${ }^{\text {iv }}$. This enabled us to physically connect with the country, to acknowledge its Elders past and present, and to be mindful of its presence in all that we did. Sitting down forced us to relax and to be present in the moment. By sitting together, the process of building relationships began. As journalism student Karen confessed,

I think at times I probably rushed writing my [journalistic] article. I didn't probably take enough time to actually sit down. [It] was hard to manage my time, so I felt like maybe my articles probably weren't as good as they could have been the firsttime round. (Karen, 2011) 
Over time, students came to realise that working this way ensured that things progressed on the community's terms. As music student James reflected,

You've got to sit back ... not being afraid of sitting around and having silence with these guys and not trying to get to know them, but just settling for a nod maybe. (James, 2009)

As James recognised, sitting down allows people to relax and places primacy on relationship building before any programme work begins. This also led to a focus on listening, which often coalesced with community power and agency. When students took the time to listen, they found community members to be generous with their sharing of knowledge about country, culture, and customs.

Respecting culture and First Peoples' worldviews

A key part of our ABSL programmes was to place control in the hands of the Aboriginal Elders and artists so that diverse ways of knowing naturally emerged. By respecting the authority of Elders and community members, students and faculty experienced new understandings of Aboriginal culture. As community partner Alan Murn explained, this allows a strengths-based approach to respecting Aboriginal cultures and worldviews to emerge.

It's really important ... that the word spreads as well about Aboriginal people and their nature and culture, the strength of it, the depth of it, the richness of it, and the incredible talent of it ... I think the students are getting a little sense of that and understand just how clever and talented and amazing that culture is, and taking that back again to mainstream culture and there would be a ripple effect from that.

(Alan, 2010)

\section{Transforming understandings and worldviews through critical reflection}

For many non-Indigenous students and faculty this experience relieved ignorance and lack of connection to Australian Aboriginal cultures and peoples. Kylie, a pre-service 
teacher, expressed profound insights regarding her own and others' understandings of Aboriginal peoples. Kylie's experiences, like many other students and faculty, led her to deeply re-evaluate past experiences and 'white' Australian society.

I used to be one of those people who was blinded by what the media chose to tell. ... So, it's changed my thinking. It's not pity: it's opening eyes. ... It's sad that the world can't respect that. It doesn't have to be right or wrong; their way is their way. (Kylie, 2012)

Kylie's comment illustrates that many students gained a new sense of respect and appreciation for Aboriginal cultures and peoples. The experience also led students to critically question and reassess their ignorance and prejudice toward other cultural groups.

\section{Ways of Being}

The second learning dimension of our framework relates to Ways of Being. As the insights and stories suggest, participants became involved in a network of relations that were reciprocal and deeply contextual (Martin, 2003). These relations determined and defined how people connected to the country where they were working, how they interacted with collaborators, and ultimately how they related to their own subjectivities - in other words, their ways of being (Martin, 2003). The Elders and community members guided this process, whether it was explaining how students connected to their collaborators in the kinship system, or modelling to them how they should behave and respond as a result. To illustrate how this played out in the three programmes, in the following sections we briefly touch on: (a) relationship building and deepening; (b) reciprocal learning and sharing; and (c) responding to contextual politics and dynamics with sensitivity.

\section{Relationship building and deepening}


The strongest theme that came from each programme was the importance of relationships. In fact, in our analysis it became difficult to isolate the relationship theme because it was so inextricably linked with the other themes. That said, there are important considerations to underscore in this discussion. These relate to the continuity of relationships, lessons that come from family and kinship, and the dynamics of relationships with partners and intermediaries.

Over time, all participants came to realise the importance of showing respect, developing trust, and taking the time to build relationships. Students built their relationships through arts-based processes, and these experiences emerged as important pathways for intercultural learning. Informal music making, cooking, or gardening sessions also provided initial introductions that become important over the course of a programme. As music student Jeffrey described, these processes facilitated a way of communicating that was much more efficient and meaningful than talking: 'Sometimes, I felt while playing that there was no need for talking. We could all understand each other very clearly’ (Jeffrey, 2011). Similarly, pre-service teacher Nick said of a community musician,

I met him while he was playing and I sat down and played with him. He didn't talk a whole bunch that first week, even though we played quite a bit together. In the second week, he did. He really opened up to me about things, what his life's been like. (Nick, 2012)

Another way in which students were initiated into thinking about relationships was by being given a skin name. ${ }^{\mathrm{v}}$ Students and faculty from two of the universities attended language and culture classes at the Papulu Apparr-Kari language centre in Tennant Creek and were given skin names as part of their welcome to the community. Through this gesture, community members were teaching us about our relationships toward one another and the culturally appropriate behaviour that accompanies these relationships. 
Many participants reported feeling at once unsure and intensely privileged to have been given a skin name and to be welcomed into the local kinship system. This can be seen in the comments of Jeff, who returned for a second year: 'you feel like you're part of a big family out there because of skin name and culture - like for me I felt like I'm going back home' (Jeff, 2012).

Numerous students and faculty members reported feeling an enduring sense of family connection to their friends and colleagues in Tennant Creek, as expressed by pre-service teacher Sharni: 'I love the remote community. It's like a little family' (Sharni, 2012). As such, family and kinship were strong elements of participants' experiences across all programmes. These elements referred to prior relationships and experiences with their own biological families as well as potentially new understandings of Aboriginal kinship systems and skin names and the importance of family and ancestors.

The intercultural experiences had a profound and sometimes transformative effect on participants. The embodied experience of participating in the programmes prompted students to engage in deeply reflective examinations of their selves, cultural subjectivities, and their perceptions of the world around them. A key element in guiding this process was the use of guided critical reflection through field diaries, focus group interviews, and informal group de-briefs. These aspects of critical reflection are crucial to the learning experiences of the students, and they also provide valuable insights about the depth of the learning experiences.

Reflecting on developing relationships and the contexts in which they were engaging, as recommended by Swords and Kiely (2010) and Hartman and Kiely (2014), students 
were prompted to think critically about difference and sameness. Some students wrote about a sense of a 'culture shock,' meaning an intense experience of cultural difference that is initially unnerving for outsiders to that culture. Other students talked of an intense awareness that while they were still in their own country, it felt as though they were in a foreign culture.

... it's culture shock on many levels for me. I'm in my own country and I don't feel familiar with a lot of things ... the real Australia is so different to what I thought it was ... my prior understandings or ideas ... have been blown out of the water. (Rhiannon, 2009)

These sorts of experiences led to complex and multifaceted changes and transformations in many participants across the three programmes. There were changes in students' and community partners' ways of viewing their professions, and there were changes in attitudes, in ways of reacting to attitudes, and in engaging with community. Many journalism students, for example, were motivated to help secure a sense of place for Indigenous people in the media, and community members voiced 'the potential to find a voice through which they might achieve fairer media representation and be able to participate on an equitable basis'.

\section{Reciprocal learning and sharing}

Another important theme to emerge in our intercultural work is the need to structure programmes so that they are mutually beneficial for community and students. This relates to the relational concept of reciprocity. Of particular relevance is the concept of generative reciprocity, which refers to the interrelatedness of people, the world around them, and the potential synergies that 
emerge from these relationships (Dostilio et al., 2012). Indigenous artist Lynette explained this from a community perspective:

It's a two-way process. I think that the musicians here have engaged with the Conservatorium students in a way that they've never engaged with other people before, other musicians, because the students are so open to new ideas and very good at what they do ... I think we've both learnt a lot from each other. (Lynette, 2009)

Similarly, after two weeks of musical and cultural exchanges with local artists in Tennant Creek, student Mitch reflected:

In learning about other people's culture and musical styles ... I saw great value in the cultural exchange that took place and realised that as an urban Australian, I really knew nothing about indigenous culture. ... Culturally, I will be able to take a lot of knowledge back home about the indigenous community that I otherwise wouldn't have learnt. (Mitch, 2010)

The reciprocal nature of these learning encounters resonates strongly with the notion of asset-based approaches to service learning, which promote respect for community members as capable agents and partners. When viewed this way, all participants were active learners with something valuable to share.

\section{Responding to contextual politics and dynamics with sensitivity}

Given that our programmes were in complex social and cultural contexts, students and faculty needed to always respond to community members and activities with great sensitivity. Specifically, the lingering devastation that colonisation continues to cause First Peoples was a major spectre in each programme. The disadvantage of regional remote communities as well as local urban communities was seen in matters such as inferior health service access and scarce employment opportunities for young people. At the same time, community members faced serious concerns such as the impact of industry on the environment, alcohol abuse, and obesity. 
A number of students experienced new understandings of poverty and disadvantage in relation to First Peoples, and the role that colonisation has played, and continues to play, in such systematic oppression. Student teachers, for example, became aware of realities and stereotypes relating to poverty and disadvantage through their interactions with school students. Students and faculty were also exposed to harsh statistics, that the probability of an Aboriginal woman experiencing domestic violence was 45 times higher than a non-Aboriginal woman (Creative Spirits, 2016). Participants of the two projects conducted in Tennant Creek spoke about alcohol-related experiences and insights. Sharni, an Aboriginal pre-service teacher, found that high school students were keen to create change:

I gave Year 10s the choice of issues. They all agreed on the issue of 'You don't need grog to have fun'.... As an Aboriginal from a city, you get told of the problems in our community in Central and Northern Australia. I'm seeing it now. I knew the stories were true, but there's a difference in hearing them and actually seeing yourself the issues with alcohol. (Sharni, 2012)

The sadness and anger experienced by some students and faculty was attributed to the loss of Aboriginal culture and language, racism, and the tragedies that have been a part of Aboriginal history since colonisation. In responding to the challenging contextual politics and dynamics, participants emphasised the value of being sensitive as well as responsive, flexible and open when engaging in intercultural relationships and experiences.

\section{Ways of Doing}

In our service learning programmes, Ways of Doing became a synthesis and articulation of ways of knowing and being. As such, it forms the third learning dimension in our framework. Ways of Doing could be seen in the arts practices, cultural customs and 
programme events; in the ways in which participants followed community protocols; and in the ways in which people engaged with one another (Martin, 2003). As we have mentioned, participants deferred to community partners about the shape of programmes and their outcomes. In the following section, we touch on this dimension of learning and engagement by focusing on: (a) the arts as a medium for connection and collaboration; (b) the design and implementation of service learning programmes to meet both community and institutional needs; (c) and the importance of building sustainable programmes with First Peoples.

\section{The arts as a medium for connection and collaboration}

What has distinguished this service-learning work has been the focus on the arts (broadly defined) as a means of meeting community identified needs and educational and artistic outcomes. Among the many benefits of this focus, we have identified the arts as a medium for facilitating expression and connection between diverse participants that other forms of communication might not have achieved. We have found these benefits to be highly compatible with First Peoples' perspectives of service learning (see also Bartleet, Sunderland \& Carfoot, 2016). To give a music-related example, participants often reflect on the act of jamming as the most appropriate and direct form of intercultural communication, describing the nature and benefits of these experiences through reference to discourses of music as a "universal" or "common language". As music student Amie says,

I've sort of reflected on the fact that music is just that common language that's sort of being able to bridge a lot of the boundaries between us. That very first thing we all kind of got in and had a listen to each other's music and had a jam and it sort of started to flow from there; whereas, if you were stuck in a room and were just chatting to each other for a few hours, you could [...] still be sitting in the room next time you come in. So, I think it was good to have that common link from the get go. (Amie, 2009) 
Likewise, music student Sophia reflected,

The strongest experience for me was being given the opportunity to listen and play along to some of the locals' original songs and bonding over the universal language of music. Another highlight was teaching the high school students in our workshops. A lot of the students were very shy and it was a beautiful experience to be able to form a connection and put a smile on their faces by teaching them something they may have never had the chance to do before. (Sophia, 2017)

\section{Meeting community and institutional needs}

The complex dynamics and intercultural learning processes described so far have been the result of careful design and planning faculty and community partners. This has involved the tricky task of balancing community and institutional needs. In terms of meeting institutional needs, as Furco (1996) outlines, service learning in higher education involves formally integrating community service with the academic curriculum. In line with Steinman (2011), while institutionalisation has led to important advantages for our programmes in terms of funding and a home within the curriculum, at times it has constrained the more fluid and personal approaches desired by community. The faculty members involved in each programme were thus presented with the complex and time-consuming task of juggling university requirements with those of community.

We have sought to achieve what Bender (2008) describes as a broader perspective on institutionalising service learning that takes into account the higher education environment and each community's needs, priorities, and activities. Bender (2008) argues for a 'socio-systemic' approach to institutional change that incorporates external, internal and personal change. Bender observes that external educational change is mandated in a top-down manner such as in higher education policies and national initiatives, whilst internal educational change deals with 'change within higher 
education institutions that initiates and promotes change within the framework of strategies, support and enabling mechanisms for curricular community engagement' (Bender, 2008, p. 129). Finally, personal change relates to changes in the way individual faculty view the 'educational approach and philosophy' of community service learning (Bender, 2007, p. 129). We have found that the design of service learning programmes with First Peoples needs to adopt this socio-systemic approach by balancing the interpersonal alongside institutional factors with broader higher education policies and initiatives on a national scale.

\section{Building sustainability into service learning programmes with First Peoples}

A final theme in our work is the need to build sustainable ABSL programmes. The communities with which we have worked are very accustomed to people flying in to deliver programmes and then quickly leaving. We have committed to developing ongoing relationships, community assets and strengths, and supporting participant morale amid frequently challenging circumstances. This has entailed a commitment to longer-term partnerships and regular returns to community.

We believe the themes and dimensions outlined in this article promote deep concepts of sustainability that have the potential to reconceptualise the design of global service learning and service learning programmes with First Peoples more broadly. The concepts focus on establishing intercultural relationships, sustaining those relationships, and sustaining transformation and hope within students and community members (see also Power, et. al., 2016). When attention is given to these deep relational concepts through the multiple learning dimensions we have discussed above, we have found that 
we can support respectful and mutually beneficial learning partnerships in a sustainable way.

\section{Conclusions: Implications for practice}

In this article, we have outlined a way of framing respectful and mutually beneficial learning partnerships through arts-based service learning with First Peoples. Underlying this has been an emphasis on collaboration and community agency. Community partners subtly control the depths to which participants travelled through and out of identified ways of learning. They also guide what people came to know, how they relate to others, and where and when this is done. As faculty members, we need to be deeply present throughout this, but we also need to make a concerted effort to let it play out without our interference. We believe this community-led learning, coupled with systematic reflective practice through fieldwork diaries, focus group interviews and digital story making, significantly deepens our students' intercultural learning experiences (see also Kiely, 2004, 2005).

It should also be said that the complex and interrelated ways in which this learning and engaging occurs are not always as neat as our framework suggests. However, the framework organises and represents a substantial amount of rich data that takes inspiration from an Aboriginal worldview and it informs how these insights can be embodied in practice. We hope that the framework will be a useful starting point for those interested in developing new partnerships with First Peoples and those committed to developing intercultural ways of learning and engaging in global service learning initiatives. We hope it will also provide a valuable reflective prompt for those in the midst of these programmes and, most of all, a beneficial reference point for evaluating these programmes in the future. 


\section{Acknowledgements}

Support for this project was provided by the Australian Government Office for Learning and Teaching (OLT).

\section{References}

Bartleet, B. L., Sunderland, N. \& Carfoot, G. (2016). Enhancing intercultural engagement through service learning and music making with Indigenous communities in Australia. Research Studies in Music Education, 38(2), 173 191

Bartleet, B. L., Bennett, D., Marsh, K., Power, A., \& Sunderland, N. (2014a). Reconciliation and transformation through mutual learning: Outlining a framework for arts based service learning with Indigenous communities in Australia. International Journal of Education and the Arts, 15(8). Retrieved from: http://www.ijea.org/

Bartleet, B. L., Bennett, D., Power, A., \& Sunderland, N. (2014b). Enhancing Indigenous content in arts curricula through service learning with Indigenous communities. Brisbane: Queensland Conservatorium, Griffith University.

Bartleet, B.L. Bennett, D., Power, A., \& Sunderland, N. (Eds.) (2016). Arts-based service learning with First Peoples: Towards respectful and mutually beneficial educational practices. New York: Springer.

Bender, Gerda. "Exploring conceptual models for community engagement at Higher Education Institutions in South Africa: Conversation." Perspectives in Education, 26, no. 1 (2008): 81-95.

Boyle-Baise, Marilynne, Rhondalyn Brown, Ming-Chu Hsu, Denisha Jones, Ambica Prakash, Michelle Rausch, Shelley Vitols and Zach Wahlquist. "Learning service or service learning: Enabling the civic." International Journal of Teaching and Learning in Higher Education, 18, no.1 (2006): 17-26. 
Creative Spirits, 2016

https://www.creativespirits.info/aboriginalculture/people/domestic-and-familyviolence\#axzz4k1uHnCGL

Dei, George Jerry Sefa, and Arlo Kempf. Anti-colonialism and education. Vol. 7. Rotterdam: Sense Publishers, 2006

Dostilio, Lina D., Barbara Harrison, Sarah M. Brackmann, Brandon W. Kliewer, Kathleen E. Edwards, and Patti H. Clayton. "Reciprocity: Saying what we mean and meaning what we say." Michigan Journal of Community Service Learning 19, no. 1 (2012): 17-33.

Furco, Andrew. "Service-learning: A balanced approach to experiential education." Expanding boundaries: Serving and learning, 1, 1-6. (1996).

Green, Madeleine F. (2009). Foreword. In Elizabeth Brewer, \& Kiran Cunningham (Eds.). Integrating study abroad into the curriculum: Theory and practice across the disciplines (pp. i-ix). Sterling, VA: Stylus Publishing, LLC.

Guffey, Jack (2008, July). Embracing an Indigenous understanding of service-learning. Keynote Address presented at the NWIC Second Summit on Indigenous ServiceLearning, North West Indian College, Bellingham, WA, USA.

Hart, Michael. (2010). Indigenous worldviews, knowledge, and research: The development of an Indigenous research paradigm. Journal of Indigenous Voices in Social Work, 1(1), 1-16.

Hartman, Eric, and Richard Kiely. "Pushing Boundaries: Introduction to the Global Service-Learning Special Section." Michigan Journal of Community Service Learning 21, no. 1 (2014): 55-63.http://globalsl.org/pushing-boundariesintroduction-to-the-global-service-learning-special-section-mjcsl/ 
Kiely, Richard. (2004). A chameleon with a complex: Searching for transformation in international service-learning. Michigan Journal of Community Service Learning, 10(2), 5-20.

Kiely, Richard. (2005). A transformative learning model for service-learning: A longitudinal case study. Michigan Journal of Community Service Learning, 12(1), $5-22$.

Lewin, Ross, ed. The handbook of practice and research in study abroad: Higher education and the quest for global citizenship. Routledge, 2010.

Longo, N., and John Saltmarsh. "New lines of inquiry in reframing international service learning into global service learning." International service learning: Conceptual frameworks and research 1 (2011): 69-85.

McMillan, Janice, and Timothy K. Stanton. "' Learning Service" in International Contexts: Partnership-Based Service-Learning and Research in Cape Town, South Africa." Michigan Journal of Community Service Learning 21, no. 1 (2014): 64-78.

Martin-Booran Mirraboopa, K. "Ways of knowing, ways of being and ways of doing: developing a theoretical framework and methods for Indigenous re-search and Indigenist research." In Power of Knowledge, the Resonance of TraditionIndigenous Studies: Conference, Australian Institute of Aboriginal and Torres Strait Islander Studies (AIATSIS), Canberra. 2001.

Miles, Matthew B., and A. Michael Huberman. "Qualitative data analysis: A sourcebook." Beverly Hills: Sage Publications (1994).

Mitchell, Carol, and Hilton Humphries. "From notions of charity to social justice in service-learning: The complex experience of communities." Education as Change 11, no. 3 (2007): 47-58. 
Molnar, Michelle Lynn. "Arts-Based Service-Learning: A Curriculum for Connecting Students to their Community." (2010). Retrieved from UMI. (No. 1483646)

Murphy, John W., and Dana Rasch. "Service-learning, contact theory, and building black communities." Negro Educational Review 59, no. 1/2 (2008): 63.

Nakata, Martin (2002). Indigenous knowledge and the cultural interface: Underlying issues at the intersection of knowledge and information systems. IFLA journal, 28(5-6), 218-221.

Noblit, George W., and R. Dwight Hare. Meta-ethnography: Synthesizing qualitative studies. Vol. 11. Sage, 1988. doi: 10.4135/9781412985000.

Porter, Maureen, and Kathia Monard. "Ayni in the global village: Building relationships of reciprocity through international service-learning." Michigan Journal of Community Service Learning 8, no. 1 (2001): 5.

Power, A. \& Bennett, D. (2015). Moments of becoming: Experiences of embodied connection to place in arts-based service learning in Australia. Asia Pacific Journal of Teacher Education 43, (2), 156-168.

Power, A., Bennett, D. \& Sunderland, N. \& Bartleet, B. L. (2016). Reconceptualizing sustainable intercultural partnerships in arts-based service learning. In B.L. Bartleet, D. Bennett, A. Power \& N. Sunderland (Eds.). Engaging First Peoples in arts-based service learning: Towards respectful and mutually beneficial educational practices (pp. 253-271).

Steinman, Erich. "' Making space": lessons from collaborations with tribal nations." Michigan Journal of Community Service Learning 18, no. 1 (2011): 5-19.

Swords, Alicia CS, and Richard Kiely. "Beyond pedagogy: Service learning as movement building in higher education." Journal of Community Practice 18, no. 23 (2010): 148-170. 
Associate Professor Brydie-Leigh Bartleet is Director of the Queensland Conservatorium Research Centre and Deputy Director (Research) at the Queensland Conservatorium Griffith University, Australia. She has worked on a range of national and international projects in community music, arts-based service learning with Australian First Peoples, intercultural community arts, and arts programmes in prison. She has worked on four successive ARC Linkage projects, led a major OLT Innovation and Development project, secured over a million dollars in research funding, and produced well over a 100 research outputs. In 2014 she was awarded the Australian University Teacher of the Year. She serves on the Board of Australia's peak music advocacy body, Music Australia, and a range of international and national boards including the International Journal of Music Education and is Associate Editor of the International Journal of Community Music.

Dawn Bennett is John Curtin Distinguished Professor of Higher Education, Director of the Creative Workforce Initiative and Chair of the Curtin Academy at Curtin University in Perth, Australia. Her research focus is the development of employability within higher education, including identity development and the nature of graduate work. Dawn retains a special interest in careers in the creative industries and continues to engage in practice-based research in music. She is also a passionate advocate for the inclusion of Indigenous cultural competencies within higher education. An Australian Learning and Teaching Fellow and Principal Fellow of the Higher Education Academy in the United Kingdom, Dawn serves numerous editorial boards and convenes the Australian Learning and Teaching Fellows' national network. She serves on the board of directors for ISME and Music Australia, and as a commissioner with the ISME Commission for Education of the Professional Musician. Publications are listed at Academia.edu.

Associate Professor Anne Power is Academic Course Advisor for the Master of Teaching Secondary Programme at Western Sydney University, Australia. Her research interests include music education, music and its relationship to other art forms, professional learning and service 
learning. Her work with service learning and disadvantaged students converges with themes of creativity. She is editor of two journals and is on several editorial boards. Anne is a co-author of several reports for state and federal education authorities. She is a 2010 winner of the ALTC Award for University Teaching for the submission Beyond Institutional Walls: Community engagement in secondary teacher education for programmes that enhance learning and she is a 2015 recipient of the Exceptional Service Award from the Professional Teachers' Council of NSW. Publications are updated on Academia.edu.

Dr Naomi Sunderland is Senior Lecturer in the School of Human Services and Social Work and member of the Music, Health, and Wellbeing Research Stream at the Queensland Conservatorium Research Centre at Griffith University. Naomi has an extensive background in participatory, creative, and community based research in the areas of health, wellbeing, and arts based community development. She has collaborated on many arts and health research projects including: the 1000 Voices Disability Life Stories Project; a social determinants of health evaluation of the Scattered People asylum seekers and refugee music group; and a participatory intercultural evaluation of multi-arts work with Barkly Regional Arts in the Northern Territory. Naomi teaches in the First Australians and Social Justice team at Griffith University and specialises in topics around transformative intercultural and immersive education, equity, and diversity. Naomi has a PhD in applied ethics and human rights from the Queensland University of Technology. She has published widely on the topics of health promotion partnerships, music and wellbeing, disability and happiness, and transformative ethics. 
${ }^{\mathrm{i}}$ In Australian Aboriginal culture, images of deceased people are not shown publicly for a period of time following their death, as a sign of cultural respect.

ii "Sorry Business" is a term used by Indigenous Australians to refer to the death of a family or community member and the mourning process.

iii "Avoidance practices" refers to those relationships in traditional Aboriginal society where certain people are required to avoid others in their family or clan.

iv "Country" is a term used by Aboriginal people to refer to the land to which they belong and their place of Dreaming. Aboriginal language usage of the word country is much broader than that in Standard English.

v The kinship system is a feature of Aboriginal social organisation and family relationships across Central Australia. Members of each kinship group have a 'skin name.' This complex system determines how people relate to each other and their roles, responsibilities, and obligations in relation to one another, ceremonial business, and land. 